\title{
Study of the Effect of Sedatives on Continuous Positive Airway Pressure Titration and Short Term Therapy Compliance
}

\author{
ROFAIDA E.M. EL-GENDY, M.Sc.*; HODA M. BAHR, M.D.*; MAI A. EISSA, M.D.**; \\ AHMED Sh. MOHAMED, M.D.* and REHAM A. AMER, M.D.** \\ The Departments of Chest* and Neuropsychiatry**, Faculty of Medicine, Tanta University
}

\begin{abstract}
Background: Obstructive Sleep Apnea (OSA) is the most common form of sleep disordered breathing and represents a major public health problem. It is caused by repetitive collapse of a narrow upper airway during sleep with periodic cessation of breathing (for more than 10 seconds). These events usually result in fragmented sleep, intermittent hypoxia and lead to excessive daytime sleepiness.
\end{abstract}

Aim of Study: We aimed to evaluate the effect of sedatives, as a method to improve over night continuous positive airway pressure titration, short-term therapy compliance, and outcomes in patients with newly diagnosed obstructive sleep apnea.

Patients and Methods: 40 Subjects in this randomized, double-blind, placebo-controlled trial were divided to group I received $3 \mathrm{mg}$ eszopiclone and group II received placebo within $60 \mathrm{~min}$ prior to the start of CPAP titration (at lights out) and, for 2 weeks as a combined therapy with CPAP before sleep, we compared the quality of CPAP titrations and Adherence to CPAP (primary outcome) during the first 4 weeks of therapy between the two groups, and evaluated improvements in symptoms (secondary outcomes) after 2 and 4 weeks of therapy.

Results: Eszopiclone significantly improved sleep titration quality (increased sleep efficiency, increased total sleep time, decreased total arousal index, decreased CPAP pressure, decreased AHI at the highest CPAP pressure) and significantly $\&$ rapidly improved short term compliance (\% of night CPAP used, mean hours/nights CPAP used, $\%$ of nights CPAP used $>4$ hours) and functional and behavioral outcomes, compared with placebo group.

Conclusion: Nonbenzodiazepine hypnotics (eszopiclone) are safe and relatively inexpensive and have the potential to improve the quality of polysomnograms or prevent studies from needing to be repeated. A short course of nonbenzodiazepines is a simple option that may facilitate better CPAP tolerance, improve therapeutic adherence, and reduce the rate of self-discontinuation of therapy. Good CPAP adherence lead to better functional outcomes.

Correspondence to: Dr. Rofaida E.M. El-Gendy, The Department of Chest, Faculty of Medicine, Tanta University
Key Words: Obstructive sleep apnea - Eszopiclone.

\section{Introduction}

THE increasing awareness of sleep disordered breathing has created a growing demand for polysomnography, resulting in excessive waiting times in many sleep laboratories [1].

Therefore, the need to develop methods to improve efficiency, increase access to care, and reduce costs is increased. Unfortunately, many patients find it difficult to fall asleep in the unfamiliar environment of a laboratory setting (the first-night effect), which may prolong sleep latency and decrease sleep efficiency [2].

Likewise, intolerance of Continuous Positive Airway Pressure (CPAP) in those initially treated or being titrated to higher levels may disrupt sleep continuity, reduce the quality of polysomnography and thus lead to inability to establish a diagnosis or titrate CPAP therapy adequately [3] .

For these reasons, the need for pre study medication with sedative hypnotics would promote a better yield of polysomnography, significant shorter sleep latency, improved sleep efficiency, improved patient tolerance of CPAP titration and subsequently better therapeutic adherence [4].

Also, these agents have minimal side effects and do not disrupt normal sleep architecture or alter respiratory events [5-7].

So, these agents ideal for use during polysomnography and could enhance the efficiency of sleep centers $[8]$

Aim of the study: The aim of this study was to evaluate the effect of sedatives, as a method to 
improve over night continuous positive airway pressure titration, short-term therapy compliance, and outcomes in patients with newly diagnosed obstructive sleep apnea.

\section{Patients and Methods}

This is a prospective, randomized, double blinded, placebo-controlled study that was carried out in Chest Department, Faculty of Medicine, Tanta University Hospitals on 40 patients with newly diagnosed obstructive sleep apnea during the period from January 2017 to August 2017.

The patients were divided into 2 groups: Group I: Included 20 patients with moderate (AHI=15:30 event/hr) to severe obstructive sleep apnea (AHI $<30$ event/h), receiving sedative hypnotic (3mg of eszopiclone) within $60 \mathrm{~min}$ prior to the start of their CPAP auto titration polysomnography. Group II: included 20 patients with moderate to severe obstructive sleep apnea, receiving placebo within $60 \mathrm{~min}$ prior to the start of their CPAP auto titration polysomnography.

All subjects were subjected to: Full history taking and complete clinical examination, Routine investigations as Complete Blood Count (CBC), liver function tests, blood sugar, blood urea and serum creatinine, ECG, arterial blood gases, Epworth sleepiness scale before and 4 weeks after CPAP therapy for outcomes evaluation, overnight complete polysomnography for recent diagnosis of obstructive sleep apnea, patients in Group I received $3 \mathrm{mg}$ eszopiclone as a sedative $60 \mathrm{~min}$ prior to the start of CPAP titration (at lights out) and, for 2 weeks as a combined therapy with CPAP before sleep, while patients in Group II received placebo, overnight complete polysomnography CPAP titration for all subjects in the same lab and environment, using (SOMON screen TM plus PSG+ Germany) which is computer based high technology polysomnography auto-adjusting CPAP device was used, short term compliance, 2 weeks, after initiating therapy and another 2 weeks after stopping medication, outcomes, sleepiness by epworth sleepiness scale, and functional by Functional Outcomes of Sleep Questionnaire (FOSQ) after 2 weeks and after 4 weeks at the end of the study duration.

\section{Statistical analysis:}

The SPSS Version 11.0 was used for data entry and statistical analysis. Descriptive statistics was expressed by mean and standard deviation for continuous variables and frequency and percentage for categorical variables. Pearson chi-square test was applied to investigate the association between categorical variables. The level of significance was set at $p$-value $<0.05$ accepted as significant.

\section{Results}

Table (1): Baseline ESS and FOSQ in Group I and Group II.

\begin{tabular}{lcccc}
\hline Baseline & Range & Mean \pm S.D & $t$-test & $p$-value \\
\hline Ess: & & & & \\
$\quad$ Group I & $7-14$ & $10.20 \pm 1.91$ & 0.027 & 0.870 \\
Group II & $7-14$ & $10.10 \pm 1.92$ & & \\
FOSQ: & & & & \\
$\quad$ Group I & $5-17$ & $11.40 \pm 4.20$ & 1.595 & 0.214 \\
$\quad$ Group II & $5-15$ & $9.80 \pm 3.81$ & & \\
\hline
\end{tabular}

Epworth sleepiness scale score mean values \pm SD in Group I and Group II were (10.20 \pm 1.91$)$ and (10.10 \pm 1.92$)$ respectively with no statistically significant difference between both groups ( $p=$ 0.870 ). Functional outcomes of sleep questionnaire score mean values \pm SD in Group I and Group II were $(11.40 \pm 4.20)$ and $(9.80 \pm 3.81)$ respectively with no statistically significant difference between both groups $(p=0.214)$.

Table (2): Diagnostic polysomnographic data (AHI, minimal desaturation, sleep efficiency, total arousal index, sleep latency, total sleep time) in Group I and Group II.

\begin{tabular}{|c|c|c|c|c|}
\hline $\begin{array}{l}\text { Diagnostic } \\
\text { polysomnographic } \\
\text { data }\end{array}$ & Range & Mean \pm S.D & $t$-test & $\begin{array}{c}p- \\
\text { value }\end{array}$ \\
\hline \multicolumn{5}{|l|}{ AHI (event/hr): } \\
\hline Group I & $29-82$ & $49.15 \pm 12.77$ & 0.950 & 0.336 \\
\hline Group II & $25-82$ & $53.35 \pm 14.40$ & & \\
\hline \multicolumn{5}{|l|}{$\begin{array}{l}\text { Minimal } \\
\text { desaturation (\%): }\end{array}$} \\
\hline Group I & $77-90$ & $81.65 \pm 3.42$ & 1.276 & 0.266 \\
\hline Group II & $65-90$ & $79.85 \pm 6.25$ & & \\
\hline \multicolumn{5}{|l|}{ Sleep efficiency } \\
\hline \multicolumn{5}{|l|}{$(\%):$} \\
\hline Group I & $55-70$ & $63.70 \pm 5.48$ & 0.013 & 0.910 \\
\hline Group II & $52-71$ & $63.50 \pm 5.61$ & & \\
\hline \multicolumn{5}{|l|}{$\begin{array}{l}\text { Total arousal index } \\
\text { (event/hr): }\end{array}$} \\
\hline Group I & $30-52$ & $39.29 \pm 6.43$ & 1.605 & 0.213 \\
\hline Group II & $32-50$ & $41.61 \pm 5.04$ & & \\
\hline \multicolumn{5}{|l|}{ Sleep latency } \\
\hline \multicolumn{5}{|l|}{$(\min ):$} \\
\hline Group I & $20-40$ & $28.60 \pm 6.13$ & 0.456 & 0.503 \\
\hline Group II & $21-42$ & $29.80 \pm 5.05$ & & \\
\hline \multicolumn{5}{|l|}{$\begin{array}{l}\text { Total sleep time } \\
(h r) \text { : }\end{array}$} \\
\hline Group I & $4.01-5.11$ & $4.40 \pm 0.34$ & 0.849 & 0.363 \\
\hline Group II & $4.01-5.02$ & $4.30 \pm 0.31$ & & \\
\hline
\end{tabular}


Apnea hypopnea index mean values \pm SD (event/hr) in Group I and Group II were (49.15 \pm $12.77)$ and $(53.35 \pm 14.40)$ respectively with no statistically significant difference between both groups $(p=0.336)$. Minimal desaturation mean values \pm SD $(\%)$ in Group I and Group II were $(81.65 \pm 3.42)$ and $(79.85 \pm 6.25)$ respectively with no statistically significant difference between both groups $(p=0.266)$. Sleep efficiency mean values \pm SD (\%) in Group I and Group II were $(63.70 \pm 5.48)$ and (63.50 \pm 5.61$)$ respectively with no statistically significant difference between both groups ( $p=$ $0.910)$. Total arousal index mean values \pm SD (event/hour) in Group I and Group II were (39.29 $\pm 6.43)$ and $(41.61 \pm 5.04)$ respectively with no statistically significant difference between both groups $(p=0.213)$. Sleep latency mean values \pm SD (minutes) in Group I and Group II were (28.60 \pm 6.13$)$ and $(29.80 \pm 5.05)$ respectively with no statistically significant difference between both groups ( $p=$ $0.503)$. Total sleep time mean values \pm SD of (hours) in Group I and Group II were (4.40 \pm 0.34$)$ and $(4.30 \pm 0.31)$ respectively with no statistically significant difference between both groups $(p=0.363)$.

Table (3): CPAP auto titration quality data (sleep efficiency, Total arousal index, sleep latency stage one, total sleep time, CPAP pressure, AHI at highest CPAP pressure) in Group I and Group II.

\begin{tabular}{|c|c|c|c|c|}
\hline $\begin{array}{l}\text { CPAP titration } \\
\text { quality data }\end{array}$ & Range & Mean \pm S.D & $t$-test & $\begin{array}{c}p- \\
\text { value }\end{array}$ \\
\hline \multicolumn{5}{|l|}{$\begin{array}{l}\text { Sleep efficiency } \\
(\%):\end{array}$} \\
\hline Group I & $69-88$ & $79.40 \pm 4.37$ & 98.915 & $0.001 *$ \\
\hline Group II & $51-70$ & $63.81 \pm 5.48$ & & \\
\hline \multicolumn{5}{|l|}{$\begin{array}{l}\text { Total arousal } \\
\text { index (event/hr): }\end{array}$} \\
\hline Group I & $14.5-30$ & $20.71 \pm 4.75$ & 180.016 & $0.001 *$ \\
\hline Group II & $30.5-50$ & $41.56 \pm 5.07$ & & \\
\hline \multicolumn{5}{|l|}{$\begin{array}{l}\text { Sleep latency } \\
(\mathrm{min}):\end{array}$} \\
\hline Group I & $3.02-21.05$ & $9.45 \pm 4.15$ & 230.154 & $0.001 *$ \\
\hline Group II & $21.3-41$ & $31.12 \pm 4.85$ & & \\
\hline \multicolumn{5}{|l|}{$\begin{array}{l}\text { Total sleep time } \\
(\mathrm{Hr}) \text { : }\end{array}$} \\
\hline Group I & $4.11-7.12$ & $5.79 \pm 0.89$ & 34.316 & $0.001 *$ \\
\hline Group II & $4-5.4$ & $4.49 \pm 0.44$ & & \\
\hline \multicolumn{5}{|l|}{$\begin{array}{l}\text { CPAP pressure } \\
\text { (mbar): }\end{array}$} \\
\hline Group I & $4.2-7.5$ & $5.94 \pm 0.94$ & 136.019 & $0.001 *$ \\
\hline Group II & 7.9-11.6 & $9.53 \pm 1.01$ & & \\
\hline \multirow{2}{*}{\multicolumn{5}{|c|}{$\begin{array}{l}\text { AHI at highest } \\
\text { CPAP pressure } \\
\text { (event/hr): }\end{array}$}} \\
\hline & & & & \\
\hline Group I & $3-12$ & $7.15 \pm 2.37$ & 98.020 & $0.001 *$ \\
\hline Group II & $10-24$ & $17.60 \pm 4.08$ & & \\
\hline
\end{tabular}

Sleep efficiency (\%) mean values \pm SD in Group I and Group II were (79.40 \pm 4.37$)$ and $(63.81 \pm 5.48)$ respectively with statistically significant increase in Group I as compared to Group II ( $p=0.001)$. Total arousal index (event/hour) mean values \pm SD in Group I and Group II were (20.71 \pm 4.75$)$ and (41.56 \pm 5.07$)$ respectively with statistically significant decrease in Group I as compared to Group II ( $p=0.001)$. Sleep latency (minutes) mean values \pm SD in Group I and Group II were $(9.45 \pm$ $4.15)$ and $(31.12 \pm 4.85)$ respectively with statistically significant decrease in Group I as compared to Group II ( $p=0.001$ ). Total sleep time (hours) mean values \pm SD of in Group I and Group II were $(5.79 \pm 0.89)$ and $(4.49 \pm 0.44)$ respectively with statistically significant increase in Group I as compared to Group II $(p=0.001)$. CPAP pressure (mbar) mean values \pm SD of in Group I and Group II were (5.94 \pm 0.94$)$ and $(9.53 \pm 1.01)$ respectively with statistically significant decrease in Group I as compared to Group II ( $p=0.001)$. AHI at highest CPAP pressure (event/hour) mean values \pm SD of in Group I and Group II were (7.15 \pm 2.37$)$ and $(17.60 \pm 4.08)$ respectively with statistically significant decrease in Group I as compared to Group II $(p=0.001)$.

Table (4): CPAP compliance data (\% of nights CPAP used) in Group I and Group II after 2 and from 2:4 weeks.

\begin{tabular}{lllcc}
\hline $\begin{array}{l}\text { \% of nights } \\
\text { CPAP used }\end{array}$ & \multicolumn{1}{c}{$\begin{array}{c}\text { After } \\
2 \text { weeks }\end{array}$} & $\begin{array}{c}\text { From } \\
2: 4 \text { weeks }\end{array}$ & $\begin{array}{c}t \text { - } \\
\text { test }\end{array}$ & $\begin{array}{c}p \text { - } \\
\text { value }\end{array}$ \\
\hline Group I & $75.90 \pm 5.42$ & $78.75 \pm 6.03$ & $t 11.572$ & 0.124 \\
Group II & $56.40 \pm 10.79$ & $68.40 \pm 11.52$ & $t 22.123$ & $0.010^{*}$ \\
$t$-test & $t 352.191$ & $t 410.702$ & & \\
$p$-value & $0.001 *$ & $0.003^{*}$ & & \\
\hline
\end{tabular}

$t$ and $p$-values for student $t$-test for comparing between the two groups. ${ }^{*} p$ : Statistically significant at $p \leq 0.05$.

t1: Student $t$-test for comparing between after 2 weeks and from 2:4 weeks in Group I.

t2: Student $t$-test for comparing between after 2 weeks and from 2:4 weeks in Group II.

t3: Student $t$-test for comparing between Group I and Group II after 2 weeks.

t4: Student $t$-test for comparing between Group I and Group II from 2:4 weeks.

Percentage of nights CPAP used after 2 weeks and from 2:4 weeks were statistically significantly increased in Group I as compared to Group II ( $p=$ $0.001),(p=0.003)$ respectively. However there was statistically insignificant difference in Group I after 2 weeks as compared to from 2:4 weeks ( $p=$ $0.124)$. But there was statistically significant increase in Group II after 2 weeks as compared to from 2:4 weeks $(p=0.010)$. 
Table (5): CPAP compliance data (mean hrs/night CPAP used for total sleep nights) in Group I and Group II after 2 and from 2:4 weeks.

\begin{tabular}{lllll}
\hline $\begin{array}{l}\text { Mean hrs/night } \\
\text { CPAP used for } \\
\text { total sleep nights }\end{array}$ & \multicolumn{1}{c}{$\begin{array}{c}\text { After } \\
2 \text { weeks }\end{array}$} & $\begin{array}{c}\text { From } \\
2: 4 \text { weeks }\end{array}$ & $\begin{array}{c}t \text { - } \\
\text { test }\end{array}$ & $\begin{array}{c}p \text { - } \\
\text { value }\end{array}$ \\
\hline Group I & $4.34 \pm 0.67$ & $4.19 \pm 0.66$ & $t_{1} 0.512$ & 0.479 \\
Group II & $2.97 \pm 0.52$ & $3.51 \pm 0.33$ & $t 29.359$ & $0.005^{*}$ \\
$t$-test & $\begin{array}{l}t 351.979 \\
t_{4} 12.951\end{array}$ & & \\
$p$-value & $0.001 *$ & $0.002^{*}$ & & \\
\hline
\end{tabular}

$t$ and $p$-values for student $t$-test for comparing between the two groups. ${ }^{*} p$ : Statistically significant at $p \leq 0.05$.

t1: Student $t$-test for comparing between after 2 weeks and from 2:4 weeks in Group I.

t2: Student $t$-test for comparing between after 2 weeks and from 2:4 weeks in Group II.

t3: Student $t$-test for comparing between Group I and Group II after 2 weeks.

t4: Student $t$-test for comparing between Group I and Group II from 2:4 weeks.

The mean hrs/night CPAP used for total sleep nights after 2 weeks and from 2:4 weeks were statistically significantly increased in Group I as compared to Group II $(p=0.001),(p=0.002)$ respectively. However there was statistically insignificant difference in Group I after 2 weeks as compared to from 2:4 weeks ( $p=0.479)$. But there was statistically significant increase in Group II after 2 weeks as compared to from 2:4 weeks $(p=0.005)$.

Table (6): CPAP compliance data (\% of nights CPAP used $>4 \mathrm{hrs}$ ) in Group I and Group II after 2 and 4 weeks.

\begin{tabular}{lllll}
\hline $\begin{array}{l}\text { \%of nights } \\
\text { CPAP used } \\
>4 \text { hrs }\end{array}$ & \multicolumn{1}{c}{$\begin{array}{c}\text { After } \\
2 \text { weeks }\end{array}$} & $\begin{array}{c}\text { From } \\
2: 4 \text { weeks }\end{array}$ & $\begin{array}{c}t \text { - } \\
\text { test }\end{array}$ & $\begin{array}{c}p \text { - } \\
\text { value }\end{array}$ \\
\hline Group I & $73.35 \pm 12.30$ & $71.70 \pm 12.27$ & $t_{1} 0.180$ & 0.673 \\
Group II & $51.95 \pm 9.39$ & $60.95 \pm 10.63$ & $t 20.223$ & $0.007^{*}$ \\
$t$-test & $t_{3} 25.210$ & $t 48.777$ & & \\
$p$-value & $0.001^{*}$ & $0.005^{*}$ & & \\
\hline
\end{tabular}

$t$ and $p$-values for student $t$-test for comparing between the two groups. ${ }^{*} p$ : Statistically significant at $p \leq 0.05$.

t1: Student $t$-test for comparing between after 2 weeks and from 2:4 weeks in Group I.

t2: Student $t$-test for comparing between after 2 weeks and from 2:4 weeks in Group II.

t3: Student $t$-test for comparing between Group I and Group II after 2 weeks.

t4: Student $t$-test for comparing between Group I and Group II from 2:4 weeks.

Percentage of nights CPAP used $>4$ hrs after 2 weeks and from 2:4 weeks were statistically significantly increased in Group I as compared to Group II ( $p=0.001),(p=0.005)$ respectively. However there was statistically insignificant difference in Group I after 2 weeks as compared to from 2:4 weeks $(p=0.673)$. But there was statistically significant increase in Group II after 2 weeks as compared to from 2:4 weeks ( $p=0.007$ ).
Table (7): Epworth sleepiness scale (baseline, after 2 weeks, after 4 weeks) in Group I and Group II.

\begin{tabular}{lllll}
\hline ESS & \multicolumn{1}{c}{ Group I } & \multicolumn{1}{c}{ Group II } & $t$-test & $p$-value \\
\hline - Baseline & $10.20 \pm 1.91$ & $10.10 \pm 1.92$ & 0.027 & 0.870 \\
- After 2 weeks & $7.25 \pm 1.25$ & $9.25 \pm 1.77$ & 16.983 & $0.001^{*}$ \\
- After 4 weeks & $6.45 \pm 1.36$ & $7.80 \pm 1.51$ & 4.875 & $0.006^{*}$ \\
- Baseline vs. & $0.001 *$ & 0.096 & & \\
$\begin{array}{l}\text { after 2 weeks } \\
\text { - Baseline vs. }\end{array}$ & $0.001 *$ & $0.001 *$ & & \\
$\begin{array}{l}\text { after 4 weeks } \\
\text { - After 2 weeks } \\
\text { vs. after 4 weeks }\end{array}$ & 0.085 & $0.001 *$ & & \\
\hline
\end{tabular}

$t$ and $p$-values for student $t$-test for comparing between the two groups. ${ }^{*} p$ : Statistically significant at $p \leq 0.05$.

Epworth sleepiness scale score after 2 weeks and 4 weeks were statistically significantly decreased in Group I as compared to Group II. $(p=0.001),(p=0.006)$ respectively. Also in Group I ESS score were statistically significant decreased on comparing the base line ESS with after 2 weeks $(p=0.001)$, and after 4 weeks $(p=0.001)$, but there was statistically insignificant difference on comparing after 2 weeks with after 4 weeks $(p=0.085)$. In Group II there was statistically insignificant difference on comparing the baseline ESS with after 2 weeks ( $p=0.096$ ), also there were statistically significant decrease on comparing the baseline ESS with after 4 weeks $(p=0.001)$ and on comparing after 2 weeks with after 4 weeks $(p=0.001)$.

Table (8): Functional outcomes of sleep questionnaire (baseline, after 2 weeks, after 4 weeks) in Group I and Group II.

\begin{tabular}{lllll}
\hline FOSQ & Group I & Group II & $t$-test & $p$-value \\
\hline - Baseline & $11.40 \pm 4.20$ & $9.80 \pm 3.81$ & 1.595 & 0.214 \\
- After 2 weeks & $17.85 \pm 1.87$ & $11.90 \pm 3.13$ & 23.311 & $0.001^{*}$ \\
- After 4 weeks & $17.35 \pm 1.63$ & $14.20 \pm 3.49$ & 9.286 & $0.004^{*}$ \\
- Baseline vs. & $0.001^{*}$ & 0.081 & & \\
$\begin{array}{l}\text { after 2 weeks } \\
\text { - Baseline vs. }\end{array}$ & $0.001^{*}$ & $0.001^{*}$ & & \\
$\begin{array}{l}\text { after 4 weeks } \\
\text { - After 2 weeks }\end{array}$ & 0.373 & $0.032^{*}$ & & \\
$\begin{array}{l}\text { vs. after 4 weeks } \\
\text { vs. }\end{array}$ & & & & \\
\hline
\end{tabular}

$t$ and $p$-values for student $t$-test for comparing between the two groups. ${ }^{*} p$ : Statistically significant at $p \leq 0.05$.

Functional outcomes of sleep questionnaire score after 2 weeks and 4 weeks were statistically significantly increased in Group I as compared to Group II. $(p=0.001),(p=0.004)$ respectively. Also in Group I there were statistically significant increase on comparing the base line FOSQ with after 2 weeks $(p=0.001)$, and after 4 weeks $(p=0.001)$, but there was no significant difference on comparing after 2 weeks with after 4 weeks $(p=0.373)$. In Group II there was statistically insignificant dif- 
ference on comparing the baseline FOSQ with after 2 weeks $(p=0.081)$, but there were statistically significant increase on comparing the baseline FOSQ with after 4 weeks $(p=0.001)$ and on comparing after 2 weeks with after 4 weeks $(p=0.032)$.

There were no serious adverse events leading to discontinuation during eszopiclone or placebo treatment.

\section{Discussion}

As regard CPAP titration quality:

Our study reported that premedication with eszopiclone during CPAP titration polysomnography significantly increased sleep efficiency, decreased total arousal index, shortened sleep latency, increased total sleep time, decreased the titrated $\mathrm{CPAP}$ pressure and decreased $\mathrm{AHI}$ at higher CPAP pressure.

These results indicated that nonbenzodiazepines sedative hypnotics are effective in facilitating sleep onset, improving sleep continuity, increasing TST, improving of respiratory events which made CPAP autotitration more compliant for most of the patients. Also improved the diagnostic yield of autotitration with reduction in total studies needing to be repeated and lowering the cost and efforts for sleep studies.

In agreement with our results Quera-Salva MA et al., 1994 [9] observed a significant increase in total sleep time-and sleep efficiency, and a decrease in wake after sleep onset. Furthermore, slow wave sleep and REM sleep were not decreased by nonBZDs (zolpidem).

Also Lettieri CJ et al., 2005 [4] found that the use of nonbenzodiazepine hypnotics results in an increase in total sleep time, an increase in sleep efficiency, and a decrease in sleep latency, mild sedation can assist with initial tolerance of CPAP therapy allowing adequate titration.

Carberry JC et al., 2017 [10] determined the effect of nonbenzodiazipene hypnotics (zolpidem) and other drugs on respiratory arousal threshold in human. They concluded that arousal threshold was $27 \%$ higher with zolpidem than placebo without impairment of genioglossus EMG activity on $\mathrm{CPAP}$ and muscle responsiveness during respiratory events; also they found no evidence for systemic reduction in central neural drive to genioglossus during sleep when upper airway resistance and therefore reflex input, is minimized with CPAP.
In contrast to the result of our study Park JG et al., 2013 [11] performed a prospective, randomized, double-blinded, placebo-controlled trial of a single dose of zaleplon 10mg or matching placebo at the start of CPAP titration during laboratory-based, split-night polysomnography (PSG) on one hundred thirty-four newly diagnosed OSA patients, to determine whether pretreatment with zaleplon immediately before CPAP titration improves 1-month CPAP adherence in subjects newly diagnosed with OSA and they found that zaleplon administered before CPAP titration PSG improved initial sleep latency without affecting minimum oxygen saturation or resultant CPAP pressure. Use of zaleplon did not result improvement in sleep efficiency or arousal indices, and thus perception of sleep quality during the PSG did not differ between the two studied groups.

These conflicting results could be explained as twenty-nine percent of successfully randomized patients did not complete the study, they also used a different hypnotic, Zaleplon.

\section{As regard CPAP compliance:}

Our study reported that A 2-week course of eszopiclone during the initiation of CPAP treatment significantly and rapidly improved short course CPAP compliance (\% of nights CPAP used, mean hrs/night CPAP used for total sleep nights and \% of nights CPAP used $>4 \mathrm{hrs}$ ) than placebo group.

In agreement with our results Drake CL et al., 2003 [3] in using nocturnal PSG variables during titration as early predictors of CPAP compliance found that patients' initial experience with CPAP treatment may be a crucial factor in determining their subsequent use of this treatment modality as individuals whose sleep improved on the CPAP titration night had nightly compliance rates of approximately 2 hours greater than patients whose sleep did not improve during titration.

In disagreement with our study, Bradshaw DA et al., 2006 [12] studied the utility of non-BZDs for improving CPAP adherence on seventy-two male OSA patients referred for CPAP treatment received an oral hypnotic agent (zolpidem), placebo pill, or neither (standard care) for the first 14 days of CPAP treatment. CPAP usage (effective mask pressure [hours per day]) was recorded. They found that administration of an oral hypnotic agent did not improve initial CPAP compliance in men with OSA.

\section{As regard the functional outcomes:}

Our study reported that CPAP using significantly improved the symptoms and behavioral out- 
comes, as measured by the ESS and FOSQ, in both groups but in Group I the improvement was more significant and more rapid on comparing to Group II.

In agreement with our results Lamphere $\mathrm{J}$ et al., 1989 [13], found that there was significant improvement in excessive daytime sleepiness comparing 1 and 14 days of CPAP use but no further improvement after 42 days of use.

Also Avlonitou E et al., 2012 [14] reported that OSAS patients who are compliant to CPAP therapy show a marked improvement in their quality of sleep and daily functioning, in contrast to patients who do not comply.

\section{Limitation of our study was:}

The number of our subjects was relatively small, so the generalizability of the findings may be restricted. Short duration of the study. Patients' tolerance to CPAP and their reasons for discontinuation were not assessed. Lack of objective data about the CPAP compliance.

\section{Conclusion:}

Nonbenzodiazepine hypnotics (eszopiclone) are safe and relatively inexpensive and have the potential to improve the quality of polysomnograms or prevent studies from needing to be repeated. To improve efficiency and reduce costs, the routine use of these agents as premedication for polysomnographic studies could be considered. A short course of nonbenzodiazepines is a simple option that may facilitate better CPAP tolerance, improve therapeutic adherence, and reduce the rate of selfdiscontinuation of therapy. Good CPAP adherence lead to better functional outcomes.

\section{Acknowledgments:}

This research was carried out without funding.

\section{Conflicts of interest:}

No conflicts of interest declared.

\section{Authors' contributions:}

All authors had equal role in design, work, statistical analysis and manuscript writing. All authors have approved the final article work.

\section{References}

1- FLEMONS W.W., DOUGLAS N.J., KUNA S.T., et al.: Access to diagnosis and treatment of patients with sus- pected sleep apnea. Am. J. Respir. Crit. Care Med., 169: 668-72, 2004.

2- KRIBBS N.B., PACK A.I., KLINE L.R., et al.: Objective measurement of patterns of nasal CPAP use by patients with obstructive sleep apnea. Am. Rev. Respir. Dis., 147: $887-95,1993$

3- DRAKE C.L., DAY R., HUDGEL D., et al.: Sleep during titration Predicts continuous positive airway pressure compliance. Sleep, 26: 308-11, 2003.

4- LETTIERI C.J., ELIASSON A.H., ANDRADA T., et al.: Does zolpidem enhance the yield of polysomnography. J. Clin. Sleep Med., 1: 129-31, 2005.

5- SALETU-ZYHLARZ G., ANDERER P., BRANDSTÄTTER N., et al.: Placebo-controlled sleep laboratory studies on the acute effects of zolpidem on objective and subjective sleep and awakening quality in nonorganic insomnia related to neurotic and stress-related disorder. Neuropsychobiology, 41: 139-48, 2000.

6- COLLEN J., LETTIERI C., KELLY W., et al.: Clinical and polysomnographic predictors of short-term continuous positive airway pressure compliance. Chest, 135: 704-9, 2009.

7- BLOIS R., GAILLARD J.M., ATTALI P., et al.: Effect of zolpidem on sleep in healthy subjects: A placebocontrolled trial with polysomnographic recordings. Clin. Ther., 15: 797-809, 1993.

8- ADLER C.H. and THORPY M.J.: Sleep issues in Parkinson's disease. Neurology, 64: 3-12, 2005.

9- QUERA-SALVA M.A., McCANN C., BOUDET J., et al.: Effects of zolpidem on sleep architecture, night time ventilation, daytime vigilance and performance in heavy snorers. Br. J. Clin. Pharmacol., 37: 539-43, 1994.

10- CARBERRY J.C., FISHER L.P., GRUNSTEIN R.R., et al.: Role of common hypnotic on the phenotypic causes of obstructive sleep apnea: Paradoxical effects of zolpidem. Eur. Respir. J., 50: 1701344, 2017.

11- PARK J.G., OLSON E.J. and TIMOTHY I.: Impact of Zaleplon on Continuous Positive Airway Pressure Therapy Compliance. J. Clin. Sleep Med., 9 (5): 439-44, 2013.

12- BRADSHAW D.A., RUFF G.A. and MURPHY D.P.: An oral hypnotic medication does not improve continuous positive airway pressure compliance in men with obstructive sleep apnea. Chest, 130: 1369-76, 2006.

13- LAMPHERE J., ROEHRS T., WITTIG R., et al.: Recovery of alertness after CPAP in apnea. Chest, 96: 1364-7, 1989.

14- AVLONITOU E., KAPSIMALIS F., VAROUCHAKIS G., et al.: Adherence to CPAP therapy improves quality of life and reduces symptoms among obstructive sleep apnea syndrome patients. Sleep and Breathing, 16 (2): 563-9, 2012. 


\section{دراسة تآثير المهدثات على معايرة جهاز ضغط الهواء الإيجابى الهمابى

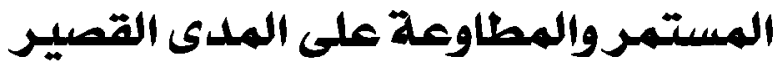

إنقطاع التنفس آثناء النوم هو الثكل الآكثر شيوعا من إضطرابات التنفس آثناء النوم ويمثل مشكلة صحية عامة كبيرة. وذلك نتيجة الإنغلاق

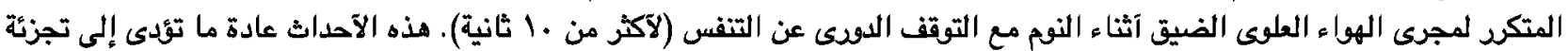

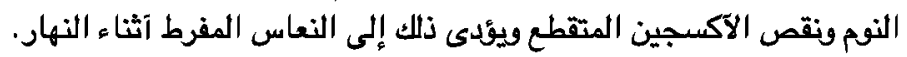

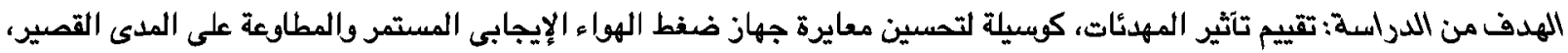

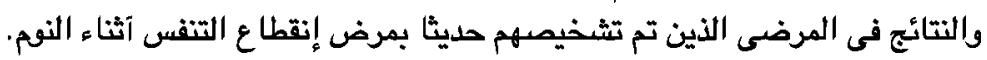

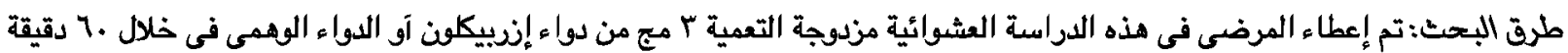

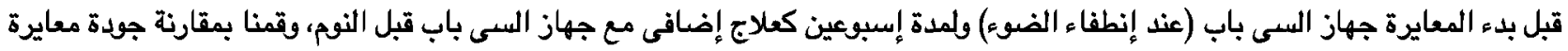

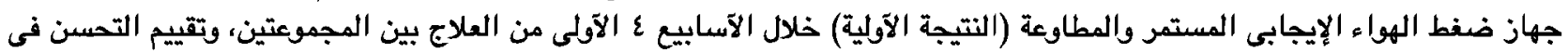
الآعراض (النتائج الثانوية) بعد إسبوعين وع آسابيع من العلاجئ.

النتائج: عقار إنوبيكلن يحسن بشكل ملحط جودة دراسدة النوم لمعايرة جهاز السى باب (زيادة كفاءة النوم، وزيادة إجمالى وقت النوم،

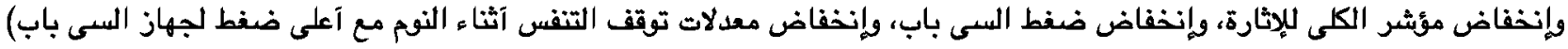

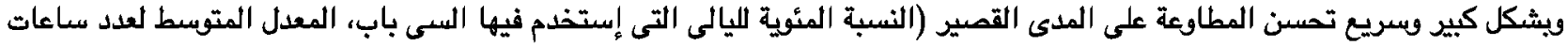
بالليالى التى إستخدم فيه السى باب النسبة المئوية لعدد الليالى التى إستخدم فيها السى باب آكئ آكتر من آربعة سـاعات) والنتائج الوظيفية والسلوكية،

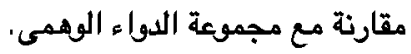

الإستتاج: الآدوية المنومة غير البنزوديازيبين (إنوبيكلهن) هي آمنة وغير مكلفة نسبيا، ولها القدرة على تصسين جودة دراسة النوم وعليه

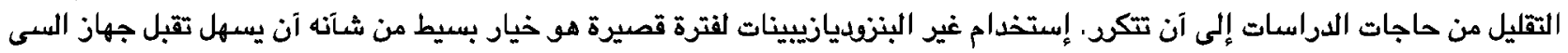

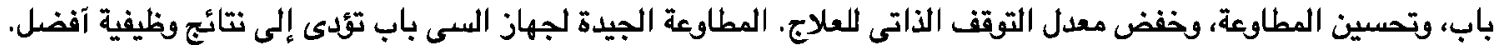

